\title{
Benchmarking Study of Hospital Libraries
}

Angela Spencer, MALS

Assistant Professor, Health Sciences Reference Librarian

Saint Louis University

St. Louis, MO

Elizabeth Mamo, MLS

Library Director

Regional Health

Rochester, NY

Brooke L. Billman, MLIS, AHIP

Senior Manager, Governance Operations

College of American Pathologists

Northfield, IL

\section{ABSTRACT}

Objectives: To assess the current landscape of hospital libraries by collecting benchmarking data from hospital librarians in the U.S. and other countries. Since the last MLA benchmarking survey in 2002 hospital libraries have faced significant changes including downsizing, position and library elimination, and hospital mergers. This survey will provide information to inform the development and implementation of effective advocacy for hospital libraries.

Methods: A web-based, anonymous survey was designed to collect information from hospital librarians representing stand-alone hospitals and hospital systems. The 57question survey was distributed via select listservs, targeting the US and Canada but open to any country. The topic areas covered hospital/health system, library, and library staff demographics; library characteristics and scope of service; interlibrary loan and document delivery; library funding; and library budget. Hospital library benchmarking surveys, including the previous MLA surveys, were reviewed and applicable questions were added.

Results: There were a total of 180 respondents, but the total number of responses for each question varied. Select results are as follows: of the responding libraries, $67.2 \%$ were part of a hospital system; $24.4 \%$ had merged with or were bought by another hospital or health system and, of those, $77.1 \%$ had acquired $1-5$ hospitals in the last 10 years; $77.9 \%$ were not for profits; over half $(55.2 \%)$ had $<5,001$ FTE in the organization; $56.9 \%$ had one library; $47.7 \%$ had 1 FTE librarian, $34.9 \%$ had $2-5 ; 82.1 \%$ did not or were not able to use social media; $60.7 \%$ didn't have strategic plans; $66.1 \%$ belonged to a consortium; $48.2 \%$ provided up to 250 search requests a year; $66.3 \%$ did not receive funding outside of their organization; $32.5 \%$ had budgets for print books totaling less than $\$ 1,000 ; 30.1 \%$ had budgets, excluding salaries, of less than $\$ 100,000$ and $9.7 \%$ had budgets over $\$ 1 \mathrm{M}$. 
Conclusions: These findings contribute to the field's knowledge of hospital library demographics as well as the services provided. The results suggest implications for hospital librarians regarding staffing levels and the depth of services within their unique settings, especially within the context of rapidly expanding health systems.

\section{INTRODUCTION}

In a time of increased health care system mergers and hospital library closures, library staff are looking for ways to advocate for the retention of services, resources, personnel, and, sometimes, the mere existence of the library. Compared to other libraries, those in hospitals face unique challenges in that they are evaluated based on their ability to generate revenue. Since hospital libraries are not usually revenuegenerating, they are often under scrutiny and the value of the library and its services are questioned. This is especially true when the hospital operating budget is cut or the organization is involved in a healthcare merger, either of which may lead to library closures.

According to KaufmannHall, in 2017 alone there were 115 health system mergers and acquisitions in the United States [1]. Hospital libraries within health systems that have merged are faced with integrating library services and resources across multiple sites. This is a task that often requires more library staff and funding, not less [2]. As these hospitals grow in services and size, library operations don't grow with them and physical space may be downsized [3] and library locations may close.

Although there does not exist a single, comprehensive resource that tracks library closures, a review of the literature reveals a disturbing trend. Over a decade ago the MLA Vital Pathways project found a decline in the number of hospitals with libraries, from $44 \%$ in 1989 to $30 \%$ in 2006 [4]. A more recent attempt to determine the rate of closures was a study in which the DOCLINE membership database was queried and it was found that 613 NN/LM member libraries had closed from 2011-2015 [5]. Harrow et al compared the 2007 edition of the Library and Book Trade Almanac with the 2017 edition and noted a $32.7 \%$ decrease in medical libraries, including hospital libraries, from 2,055 in 2007 to 1,384 in 2017 [6].

Previous hospital benchmarking studies are now outdated, especially with the increase in health care mergers and library closures. The aim of this study was to collect data about hospital library characteristics, services, populations served, and budgets. This information will provide library staff and hospital administrators with current data to inform their plans for library services. Library staff can also use this information when advocating for the needs of their libraries. 


\section{HISTORY OF HOSPITAL LIBRARY BENCHMARKING}

Hospital library benchmarking studies have been conducted since the early 1960s, beginning with a survey by the American Hospital Association's Division of Research which collected information from a sample of hospitals in their registry. Select data was analyzed and it was recommended that improvements were needed for libraries to function successfully [7].

The American Medical Association, in partnership with Case Western Reserve University and the American Hospital Association, issued three surveys (1969,1973, 1979) of health sciences libraries which resulted in the publication of the Directory of Health Science Libraries in the United States [8-10]. Each edition of the directory provided a listing of libraries by state and name. The directories contained a breakdown of libraries by sponsoring organizations and by number of staff. Crawford analyzed results of the three surveys to determine patterns, growth, or decline. Overall there was in increase in the number of libraries in hospitals in the 10-year period [11].

By the 1980s, hospitals were experiencing an increase in health care costs and institutional mergers. Wos surveyed hospitals that were part of multi-site systems; data illustrated the impact of mergers on library collections, staffing, and budgets [12]. In 1990, hospital libraries in Michigan provided survey responses for two time periods and it was concluded that these libraries were adversely affected by mergers with noted reductions in staff, hours, and resources [13]. The author called for the ongoing collection of hospital library data. Also in 1990, the American Hospital Association surveyed registered hospitals in the United States [14]. Two years later, Glitz conducted a survey of hospital libraries in the Pacific Southwest Medical Library region, comparing the data to the 1989 version of the same survey, noting decreases in libraries and staff [15].

In the late 1990s MLA observed an increase in closures of hospital libraries and established the MLA Benchmarking Network. Dudden described the development of a task force to create a benchmarking tool, issue surveys, and share the results with MLA members [16]. Surveys were distributed in 2002 and 2004 and select data were presented in publications, conference proceedings, and made available on an interactive website. MLA members could select parameters applicable to their situation and obtain data to share with their administrators. For example, Bertolucci used the data to increase her library's book budget [17] and Fama used the data to revise her library's hours of operation [18]. The MLA Hospital Libraries Section Standards Committee used the data to develop and publish a formula for library staffing, which was included in the 2002 MLA Hospital Libraries standards [19].

Meanwhile, MLA's support evolved into the task force on Vital Pathways for hospital libraries. The task force distributed a new survey in 2005. Thibodeau compared the results of the 2005 survey to the 1989 American Hospital Association survey results and noted a decrease in staffing [4]. Thibodeau also noted the need to track the status 
of hospital libraries as there wasn't a way to accurately quantify closures. Later that decade VanMoorsel distributed a survey of hospital library staffing and compared the results to the MLA standards for Hospital Libraries, finding a negative variance from the MLA standard [20]. Similarly, Ducas surveyed Canadian hospital libraries in 2012 and compared the results to the Canadian Hospital Library Association (CHLA) standards for library staffing and found that many libraries did not have a master's prepared librarian, or adequate staffing levels according to the CHLA Standards [21].

\section{METHODS}

In August 2017 an online survey using SurveyMonkey was distributed in order to collect and assess hospital library benchmarking data. A three-member planning team developed and pilot-tested the survey instrument (Appendix A), consisting of 57 questions with integrated skip logic. The survey was reviewed and determined to be exempt from human subject review by the Institutional Review Board at Rochester Regional Health on July 19, 2017. The call to participate in the survey was sent to various health science librarian online distribution lists including MEDLIB-L and the MLA Hospital Libraries Section on August 16, 2017 and the survey closed on September 15, 2017. Reminders were sent during this period. Identifying information, such as IP address, respondent name, and organization name, was not collected. The survey indicated that just one library representative from each hospital or hospital system should fill out the survey. For open-ended questions the constant comparative method was used; two authors independently coded the responses and resolved discrepancies through discussion [22]. A total of 180 respondents participated in the survey.

\section{RESULTS}

Institutional characteristics

Of the total responses, $91.6 \%$ were from the United States, $7.3 \%$ from Canada, and $1.1 \%$ from New Zealand. One-third (32.8\%) of respondents indicated they were from a hospital that is not part of a health system while two-thirds $(67.2 \%)$ were. About thirty percent (30.1\%) were from a system with $2-5$ hospitals, $12.5 \%$ with $6-10,6.8 \%$ with $11-15$, and $18.2 \%$ with more than 15 . The majority of respondents $(30.5 \%)$ indicated they were from hospitals/hospital systems that had 201-500 beds, while $16.7 \%$ had 200 or fewer beds, $20.7 \%$ had $501-1,000,14.4 \%$ had between $1,001-2,000$ beds, and $17.8 \%$ had more than 2,001 beds. Just $8.7 \%$ of hospitals/health systems had 1,000 or fewer full time equivalent (FTE) employees while $46.5 \%$ had 1,001-5,000 FTE, $16.9 \%$ had $5,001-10,000$ FTE, $20.9 \%$ had $10.001-50,000$, and $6.9 \%$ had over 50,001 FTE. Most $(91.0 \%)$ of the respondents were from teaching hospitals. Twenty-four percent $(24.4 \%)$ of the respondents' hospital or hospital systems had merged or been acquired by another organization in the last 10 years. Of the locations that have 
acquired hospitals, $77.1 \%$ had acquired $1-5$ sites, $10.8 \%$ acquired $6-10$ sites, and $12.1 \%$ had acquired 11 or more sites.

\section{Library characteristics}

Over half (56.9\%) of all respondents had 1 library within their hospital/hospital system, $32.8 \%$ had $2-5$ libraries, $5.2 \%$ had $6-10$, and $5.2 \%$ had more than 10 libraries. Figure 1 is a cross tabulation of the number of libraries and the number of hospitals and Figure 2 is a cross tabulation of number of libraries and number of beds. Half $(50.0 \%)$ of respondents indicated that their library supported 1 hospital while $31.2 \%$ supported $2-5$ hospitals, $9.4 \%$ supported $6-10$, and $9.4 \%$ supported more than 10 . The number of FTE librarians ranged from fewer than 1 to more than $15: 5.8 \%$ had fewer than 1 FTE, $50.6 \%$ had $1 \mathrm{FTE}, 35.5 \%$ had $2-5,2.9 \%$ had $6-10$, and $4.6 \%$ had more than 10 . One respondent $(0.6 \%)$ was not an employee but a volunteer. Figure 3 is a cross tabulation of librarian FTE and number of sites supported. Half (52.0\%) of libraries did not have support staff while $39.3 \%$ had $1-3,6.9 \%$ had $4-7$, and $1.7 \%$ had 8 or more staff.

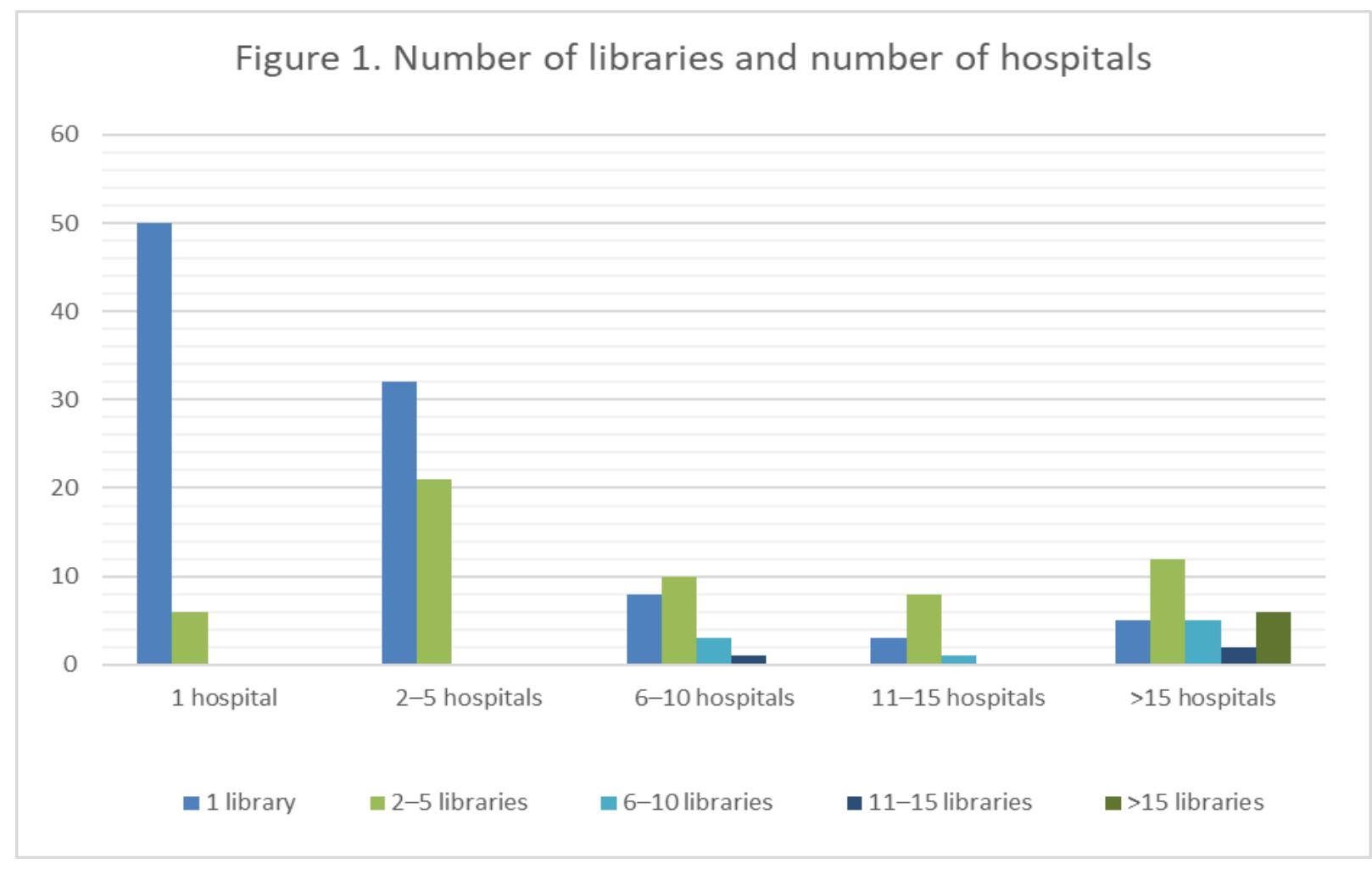


Figure 2. Number of libraries and number of beds

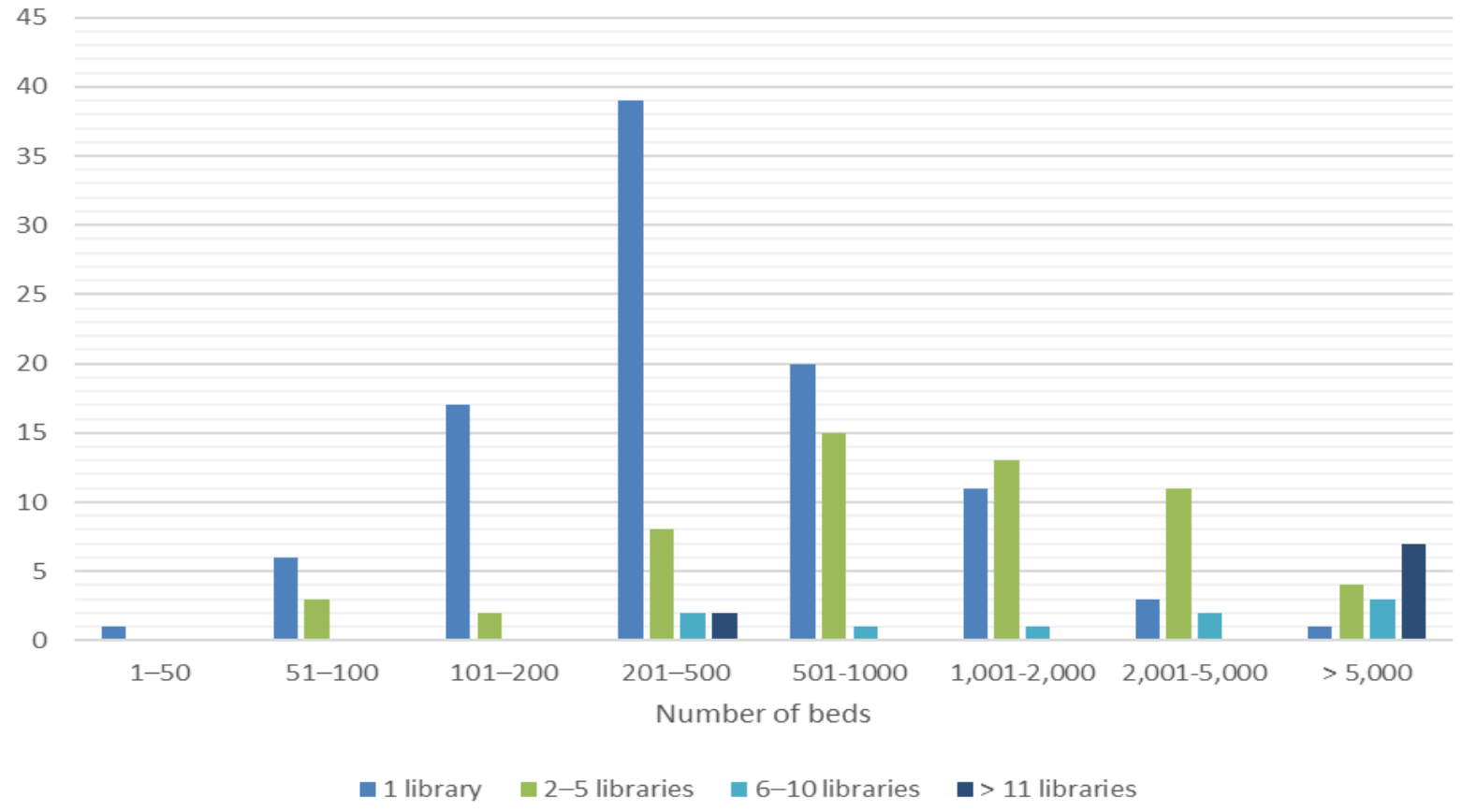

Figure 3. Hospital librarian FTE and number of hospitals supported

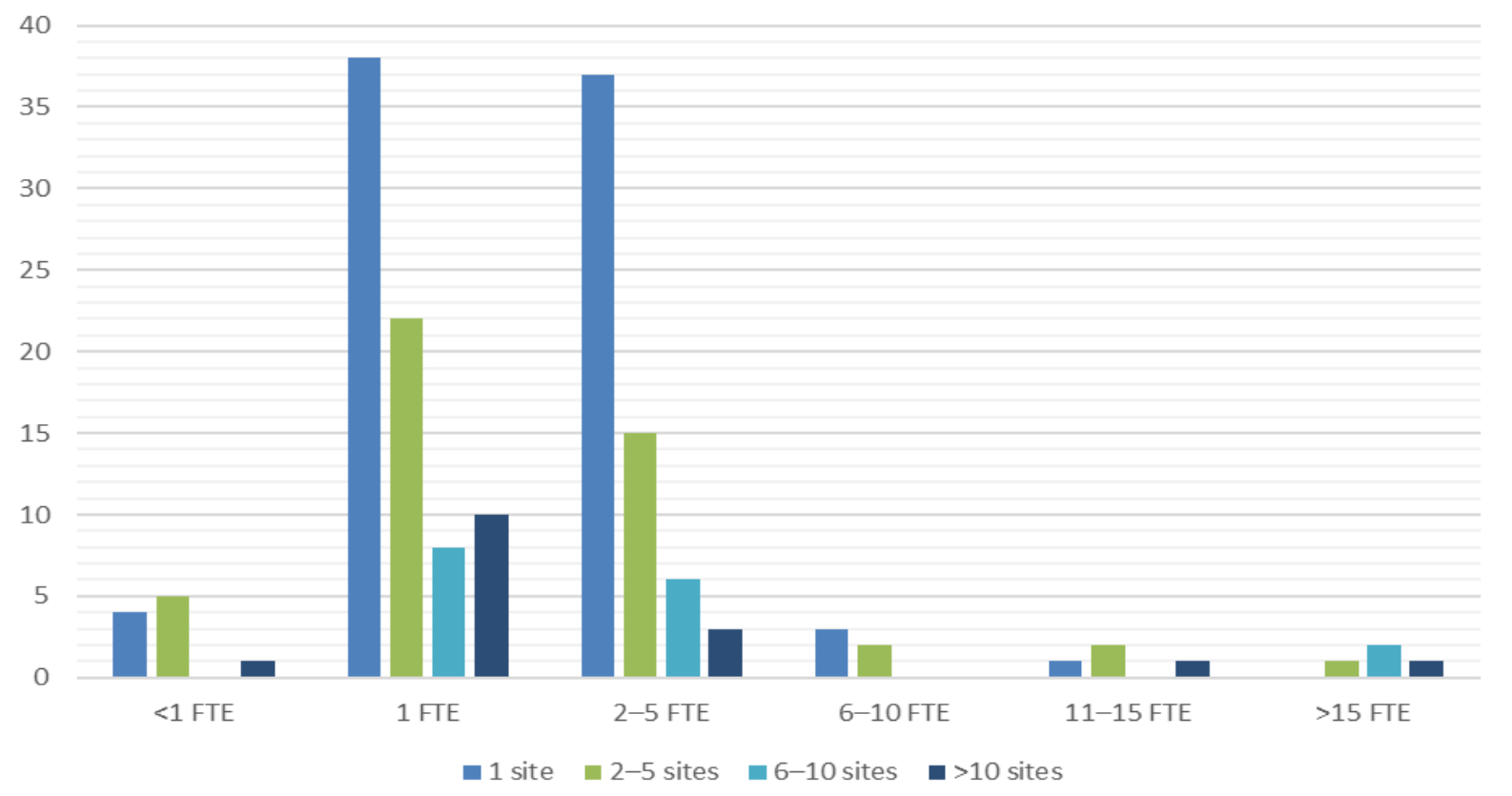

The department(s) the library/libraries reported to included education (e.g., graduate medical education, nursing education) (44.1\%), administration (41.3\%), 
information technology (6.1\%), human resources $(5.6 \%)$, research services $(4.5 \%)$, and other departments $(6.7 \%)$. The majority of libraries $(60.7 \%)$ did not have a strategic plan and $78.8 \%$ did not have a formal marketing or communications plan. Almost all (97.1\%) respondents had physical library space.

Many $(40.6 \%)$ respondents did not have a library website. Of the respondents who did, the following departments managed it: library (50.0\%), marketing $(29.0 \%)$, information technology (16.0\%), public affairs (3.0\%) and other (2.0\%). Most (91.7\%) of respondents had an internal library website or intranet. Of those respondents, the following departments managed it: library (66.2\%), information technology (22.1\%), and marketing $(11.7 \%)$. Off-site access to electronic resources was provided by the hospital $(39.2 \%)$, the library (34.5\%), both the hospital and library (12.9\%), 10.5\% provided no access off-site, and $2.9 \%$ were unsure. Most (84.4\%) libraries did not use social media. Most (80.7\%) library staff did not have access to the electronic health record while $9.4 \%$ had full access and $9.9 \%$ had access only to the module that allows staff to provide links to resources (e.g., via the InfoButton feature.)

\section{Populations served}

Most health care professionals are served by the library with respondents indicating they serve nurses (94.6\%), physicians, $(94.0 \%)$, pharmacists $(92.2 \%)$, allied health staff $(89.8 \%)$, residents $(78.3 \%)$, and other clinical staff not already categorized (88.6\%). Others served include administration/management (92.2\%), students (85.5\%), researchers $(76.5 \%)$, patients $(61.4 \%)$, faculty $(59.0 \%)$, visitors $(56.6 \%)$, and other nonclinical staff not already categorized (83.1\%).

Of the respondents who provided services to residents, $63.6 \%$ served up to 100 residents, $31.0 \%$ served $101-500$ residents, and $5.4 \%$ provided services to over 500 residents. A cross tabulation of librarian FTE and number of residents served is available in Figure 4. Of the respondents who provided services to fellows, $89.4 \%$ served up to 100 fellows and $10.4 \%$ served over 100 fellows. 
Figure 4. Librarian FTE and number of residents

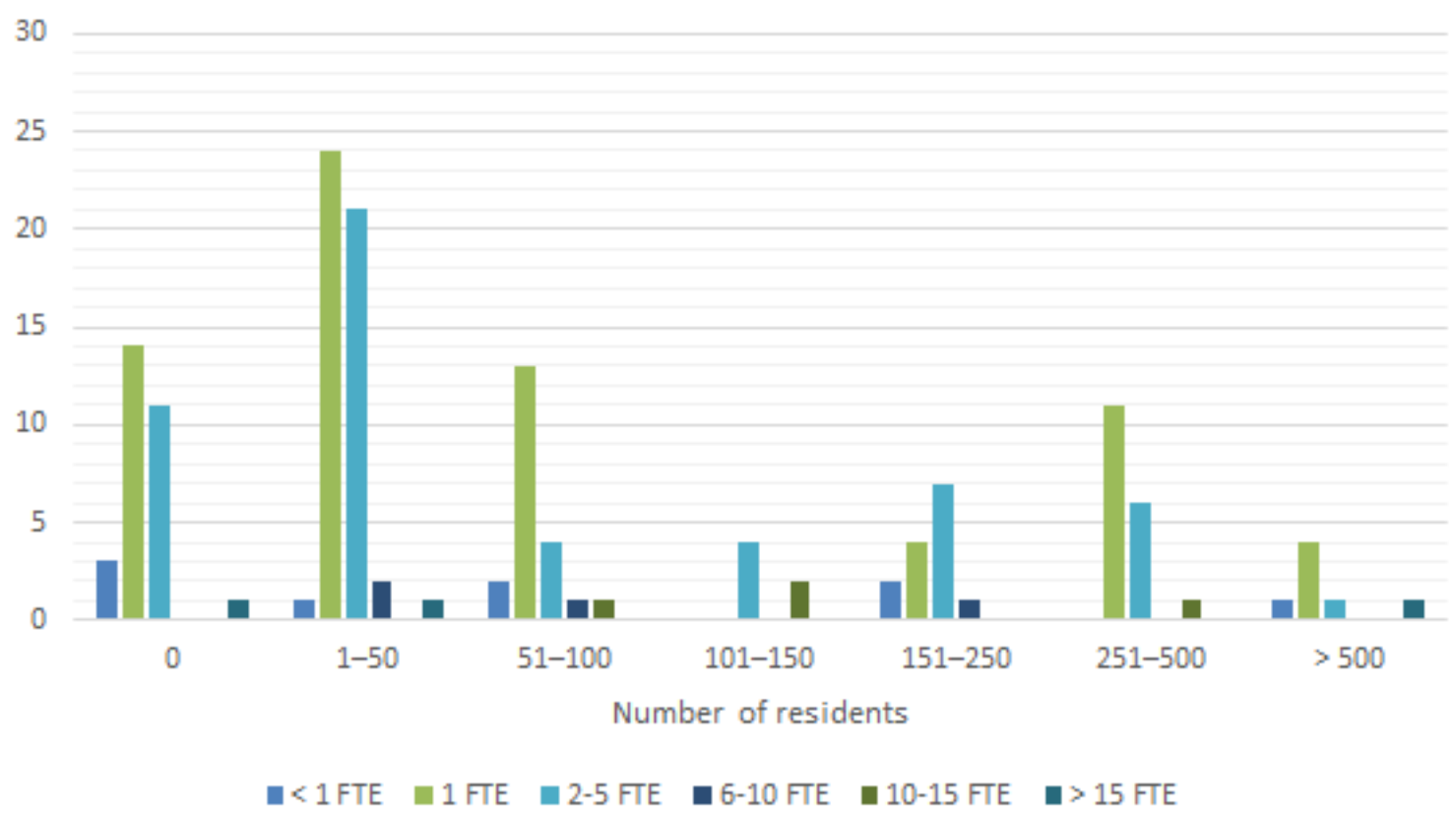

Library services

Respondents selected services provided by their libraries. "Other" responses were coded and included in Table 1.

Table 1. Services provided by respondents

\begin{tabular}{|c|c|}
\hline Services & $\%$ \\
\hline Literature searching & $100.0 \%$ \\
\hline Interlibrary loan & $98.8 \%$ \\
\hline Teaching/instruction & $87.4 \%$ \\
\hline Cataloging & $85.0 \%$ \\
\hline Intranet/internet pages & $72.0 \%$ \\
\hline Meeting space & $60.5 \%$ \\
\hline Patient education & $52.7 \%$ \\
\hline Consumer health & $52.1 \%$ \\
\hline
\end{tabular}


RESEARCH

\begin{tabular}{ll} 
Publishing support & $45.5 \%$ \\
\hline Systematic reviews & $32.3 \%$ \\
\hline LibGuides & $30.5 \%$ \\
\hline CME & $23.4 \%$ \\
\hline Clinical medical librarian program/patient care rounding & $22.2 \%$ \\
\hline Media services & $11.9 \%$ \\
\hline Data management & $12.0 \%$ \\
\hline Internal Review Board & $9.0 \%$ \\
\hline Social media & $5.4 \%$ \\
\hline
\end{tabular}

The number of search requests respondents received each year ranged from up to 100 (20.5\%), 101-250 (27.7\%), 251-500 (21.1\%), 501-750 (10.2\%), 751-1,000 $(10.2 \%)$, and more than $1,000(10.2 \%)$. Figure 5 is a cross tabulation of the number of searches and hospital/system FTE and Figure 6 is a cross tabulation of the number of searches and bed count. Most (86.7\%) of respondents received consumer health questions and, of those who did, $57.3 \%$ received up to 25 questions a year while $21.0 \%$ received $26-100$ questions and $21.7 \%$ received over 100 questions a year. A third $(34.1 \%)$ of respondents maintained the hospital/health system archives. 
Figure 5. Number of searches and hospital FTE

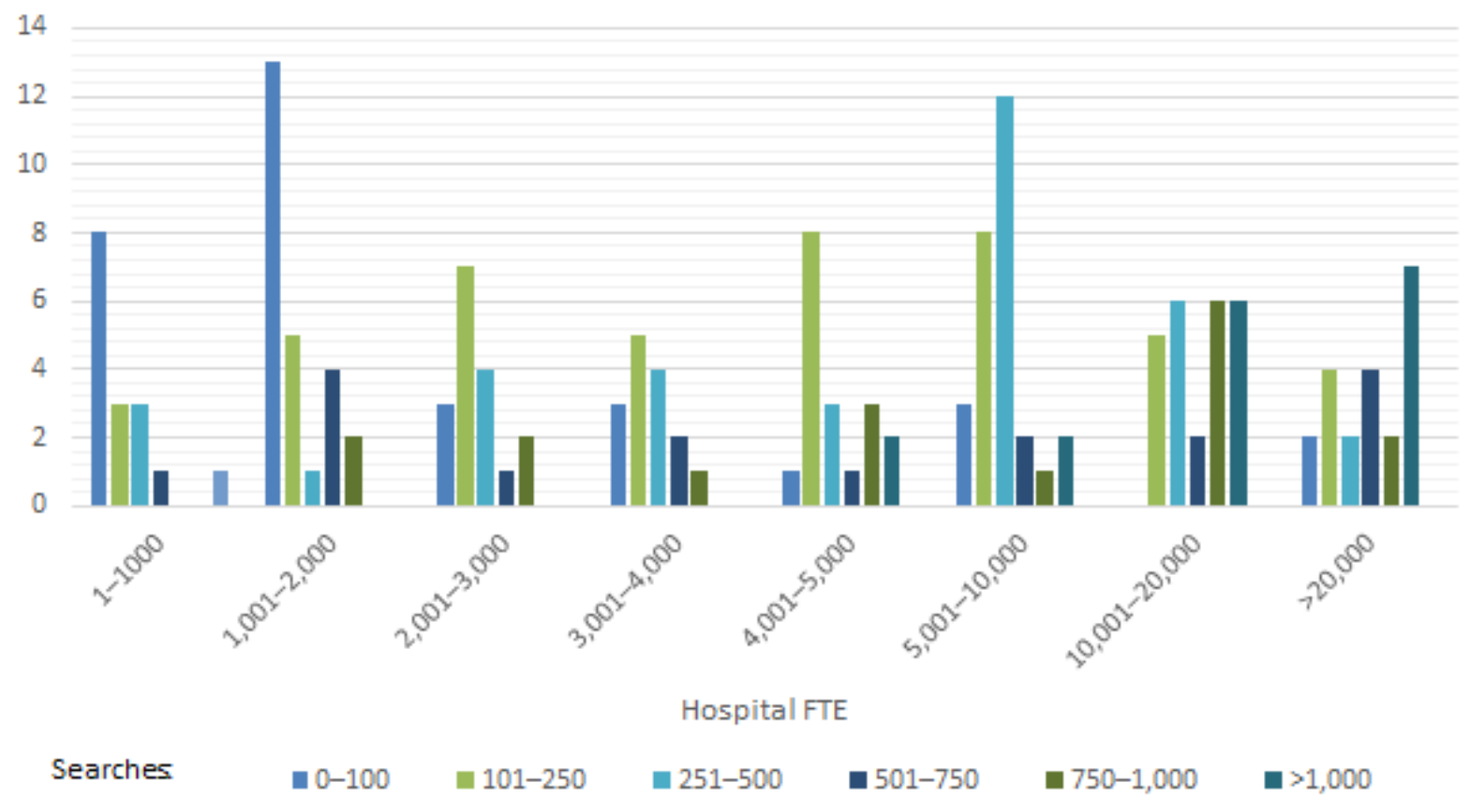

Figure 6. Number of searches and bed count

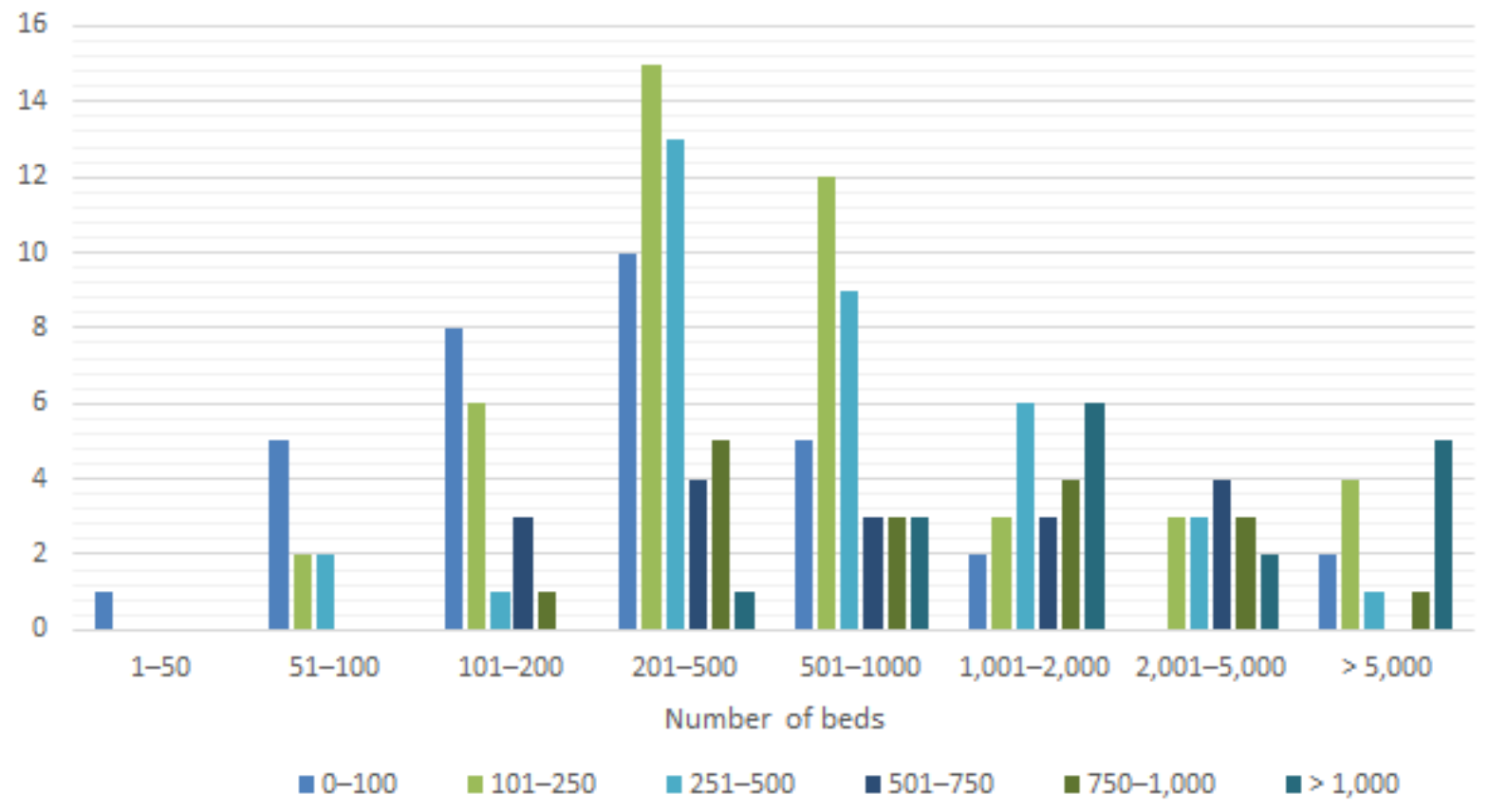

Respondents provided the following number of articles from their collection to those within their organization in one year: up to 250 (22.5\%), 251-500 (6.9\%), 5011,000 (18.1\%), 1,001-2,500 (15.6\%), 2,501-5,000 (11.9\%), and over 5,000 (25.0\%). 
Figure 7 is a cross tabulation of document delivery requests and hospital/hospital system FTE. Articles requests filled each year via interlibrary loan (ILL) were as follows: up to 100 (21.3\%), 101-250 (17.7\%), 251-500 (20.1\%), 501-1,000 (15.2\%), 1,001$2500(13.4 \%), 2,501$ or more $(12.2 \%)$. Figure 8 is a cross tabulation of the number of ILL requests and hospital/hospital system FTE.

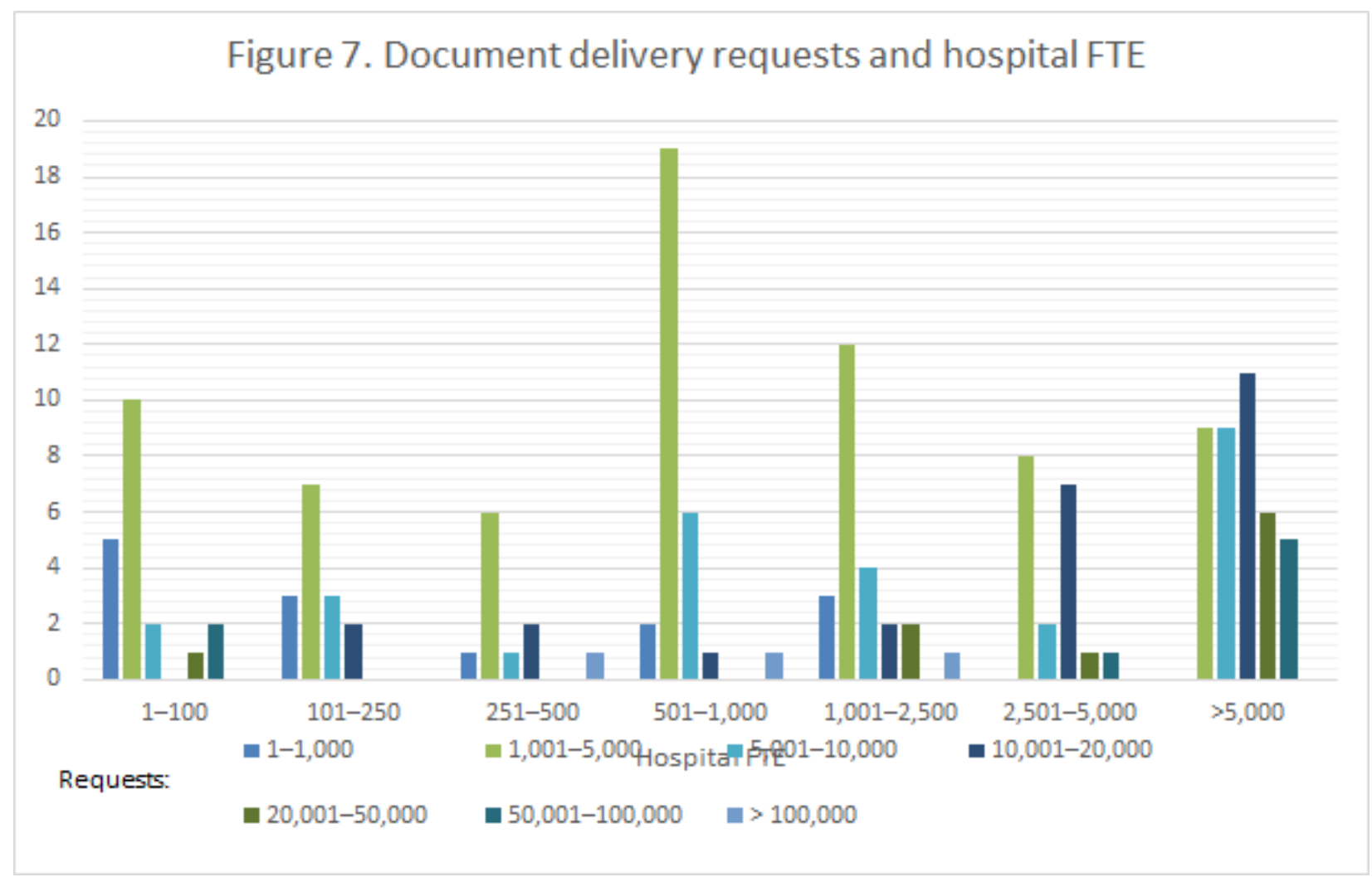


Figure 8. ILL requests and hospital FTE

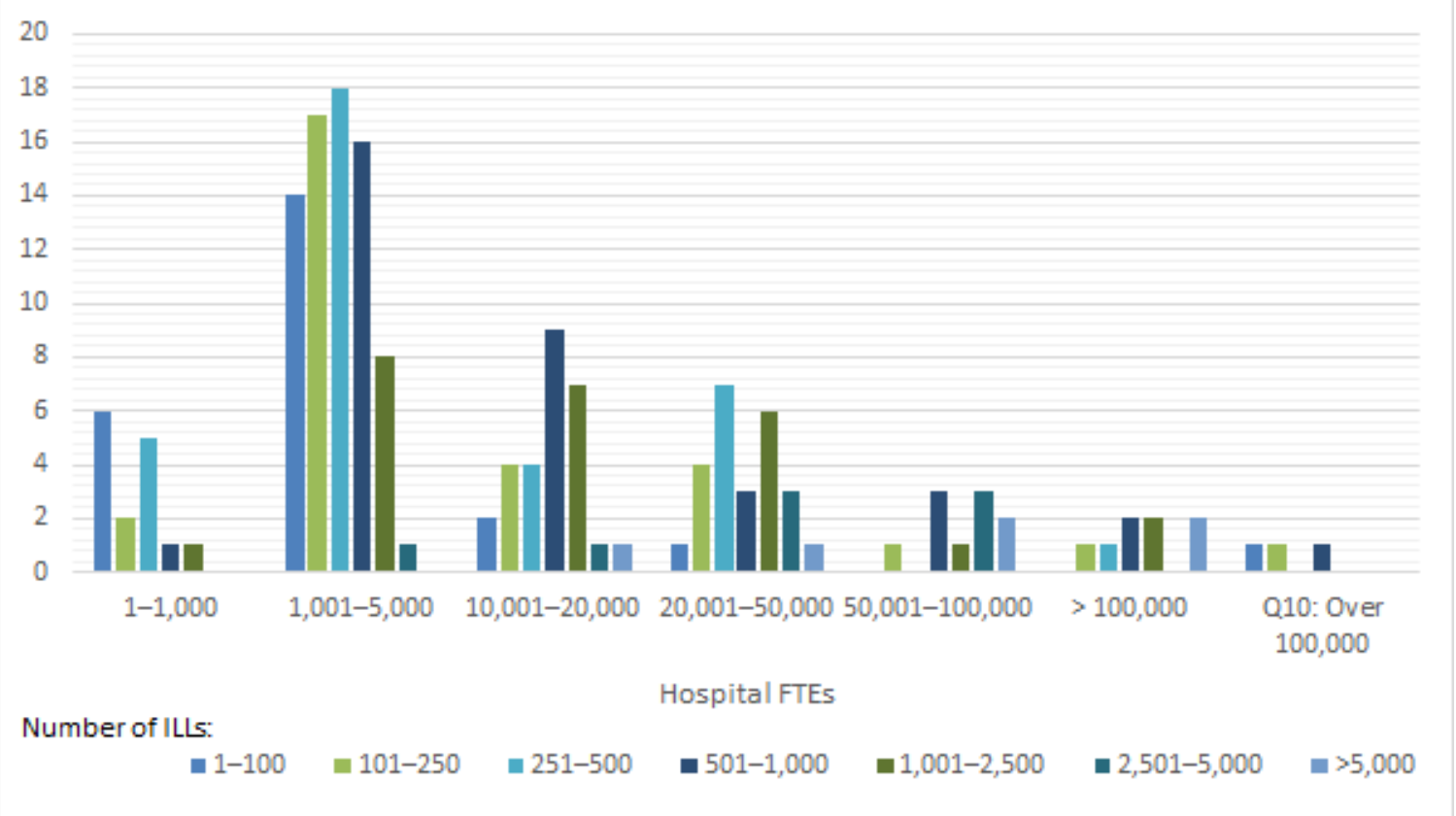

Two thirds of respondents (68.1\%) spent up to $\$ 1,000$ a year on article requests, excluding copyright fees, $24.1 \%$ spent between $\$ 1,001-\$ 5,000$, and $7.8 \%$ spent over $\$ 5,000$. Most respondents (83.0\%) spent up to $\$ 500$ a year on copyright fees. The response to whether the library was a Loansome Doc provider was almost split with $45.2 \%$ indicating they were. Almost half of the libraries (47.9\%) borrowed up to 10 physical books a year from other libraries, while $34.5 \%$ borrowed $11-50$, and $17.6 \%$ borrowed more than 50 per year. Most respondents (71.7\%) lent up to 10 books a year to other libraries.

\section{Library budgets}

Budgets, excluding staff salaries, varied greatly with $12.2 \%$ up to $\$ 50,000,17.9 \%$ from $\$ 50,001-\$ 100,000,19.2 \%$ from $\$ 100,001-\$ 200,000,28.8 \%$ from $\$ 200,001-$ $\$ 500,000,12.1 \%$ from $\$ 500,001-\$ 1,000,000,5.8 \%$ from $\$ 1,000,001-\$ 2,500,000,2.6 \%$ from $\$ \$ 2,500,001-\$ 5,000,000$, and $1.3 \%$ over $\$ 5,000,000$. Figure 9 is a cross tabulation of library budgets and hospital FTE. 


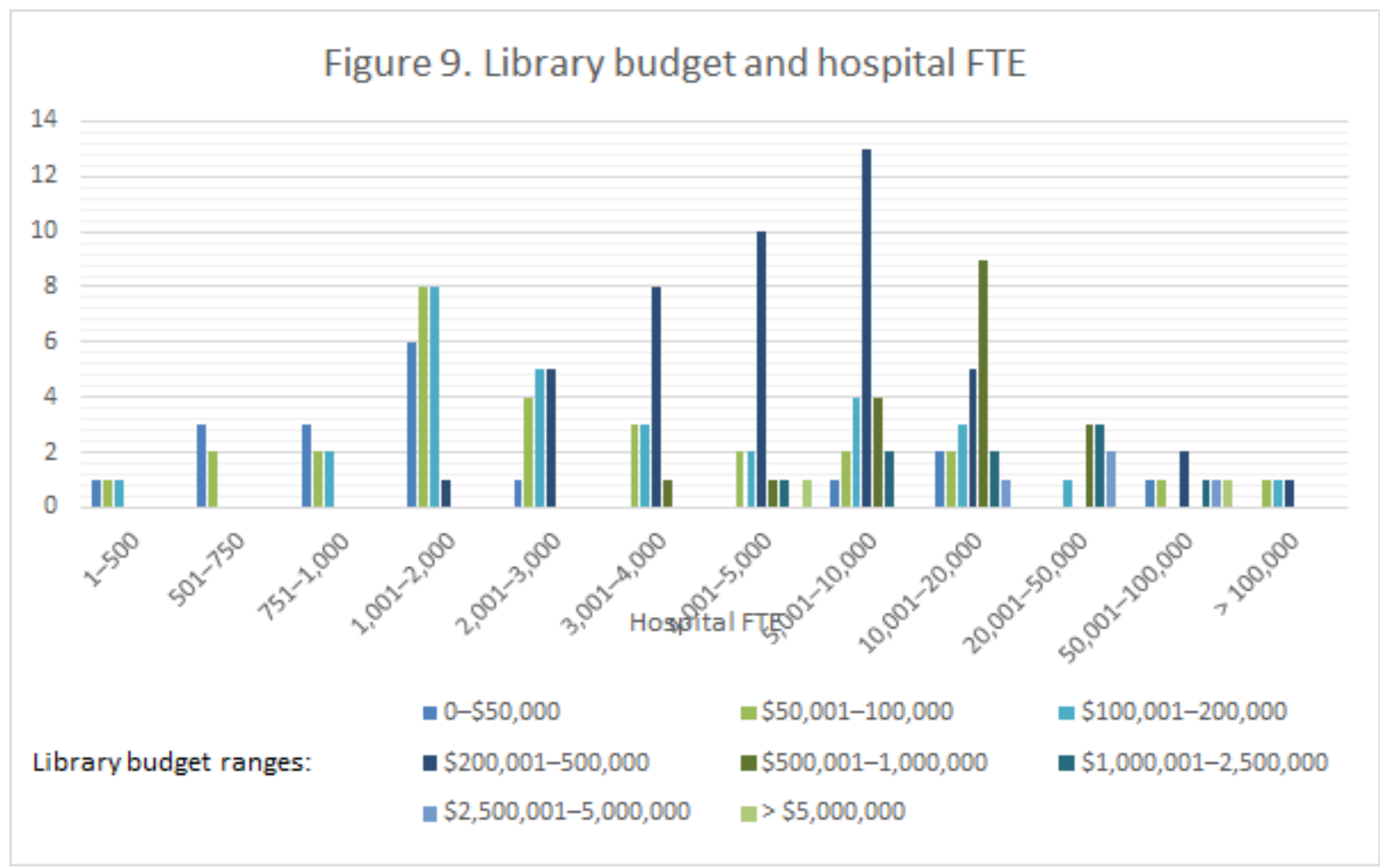

For staff salaries, $11.5 \%$ of respondents had a total budget for staff salaries, excluding benefits, of up to $\$ 50,000$ while $34.6 \%$ had budgets from $\$ 50,001-\$ 100,000$, $33.3 \%$ from $\$ 100,001-\$ 250,000,13.5 \%$ from $\$ 250,001-\$ 500,000$, and $7.1 \%$ over $\$ 500,001$. Figure 10 is a cross tabulation of library salary budget, excluding benefits, and hospital FTEs available. 


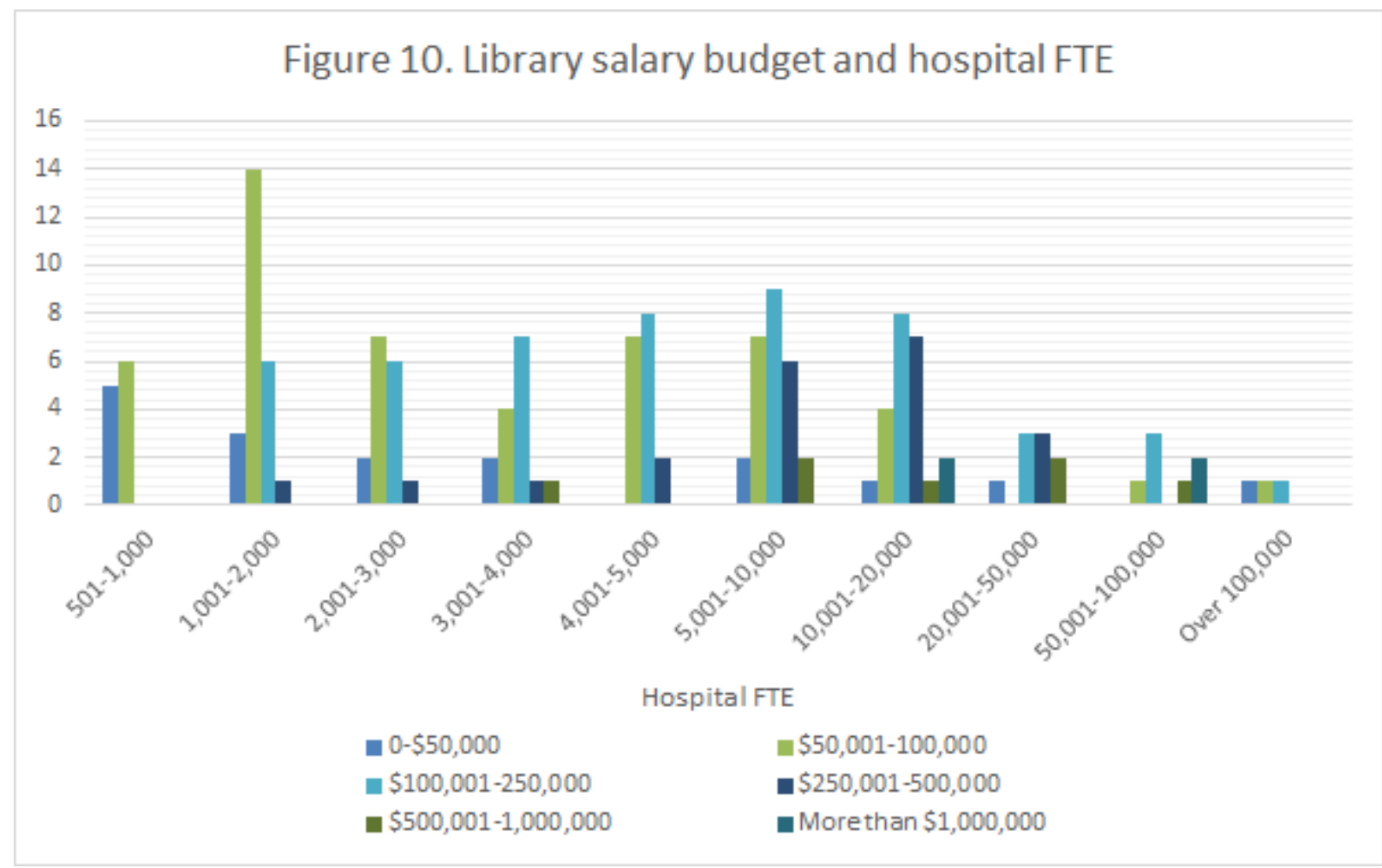

Over a third (39.6\%) of respondents had a journal budget of up to $\$ 50,000$, $22.0 \%$ from $\$ 50,001-100,000,22.0 \%$ from $\$ 100,000-250,000,8.2 \%$ from $\$ 250,001-$ $500,000,5.1 \%$ from $\$ 500,001-\$ 1,000,000$, and $3.1 \%$ over $\$ 1,000,000$. 
Figure 11 is a cross tabulation of journal budgets and hospital FTEs.

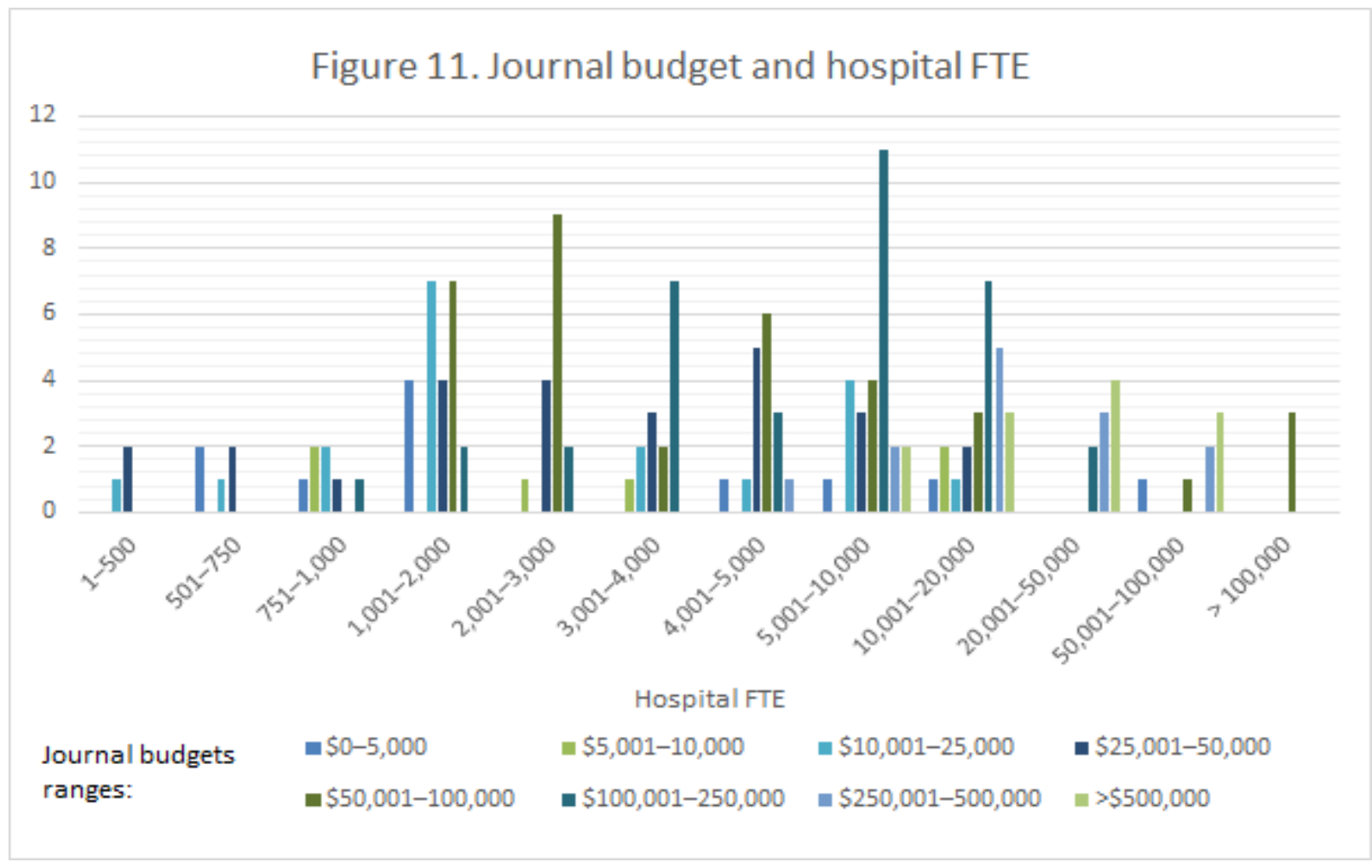

For ebook budgets, $22.8 \%$ spent up to $\$ 500 ; 19.0 \%$, $\$ 501-5,000 ; \$ 18.4 \%$, $\$ 5,001-20,000 ; 12.0 \%, \$ 20,001-50,000 ; 16.5 \%, \$ 50,001-100,000$; and $11.4 \%$ were over $\$ 100,000$. The majority (26.1\%) of respondents spent $\$ 50,001-100,000$ on database budgets (which excluded point of care tools) while $21.5 \%$ spent up to $\$ 10,000$, $16.4 \%$ spent $\$ 10,001-25,000,15.0 \%$ spent $\$ 25,001-50,000$, and $20.9 \%$ spent more than $\$ 100,000$. Almost a third of respondents (32.5\%) had a print book budget of up to $\$ 1,000,30.7 \%$ had a budget of $\$ 1,001-5,000,20.6 \%$ had a budget of $\$ 5,001-\$ 10,000$, and $16.3 \%$ had a budget of over $\$ 10,000$. Most libraries (66.1\%) belonged to a consortium and, of those, three-quarters (74.8\%) allocate up to $25 \%$ of their budget to consortium purchased products while $14.4 \%$ allocate $26-40 \%, 8.1 \%$ allocate $41-60 \%$, and $2.7 \%$ allocate more than $60 \%$. Over a third of respondents (35.6\%) did not have a point of care tool or did not pay for one.

Most libraries (66.3\%) do not receive funding outside of their organization. One quarter $(26.3 \%)$ received donations, $18.1 \%$ generated funds from ILL, $16.9 \%$ received grants, $4.4 \%$ generated funds from non-systematic review mediated searches, and $0.6 \%$ generated funds from a systematic review service. 


\section{DISCUSSION}

We were unable to calculate the survey sample size, and therefore response rate, as there is no source documenting the current number of hospital libraries in existence. We found we could not compare our response rates or survey results to Dudden [16] or Thibodeau [4] as we asked participants to coordinate one survey response for each organization (as compared to previous studies in which any library staff representative could participate). Requesting one respondent per organization was done in an attempt to minimize duplicate data. The inability to compare our data to previous studies is indeed problematic; this speaks to the difficulty in collecting data representative of the current landscape while minimizing the possibility of duplicative responses.

Related to organizational responses, we found that some hospital libraries, despite being a member of a health care system, do not work closely with others from the same system and don't have information (e.g., library characteristics, budget, resources, search statistics) about the other locations. Respondents commented that health care systems have libraries with partially or entirely separate budgets and function autonomously. It is unclear if some responses reflect one or multiple hospitals.

The landscape of hospital librarianship is changing so it was difficult to hypothesize what the survey data would reveal. We presumed there would be a steady increase in budgets as the size of the organization increased but this wasn't indicated (see Figure 6). We also speculated there would be a correlation between the number of librarians and the number of hospitals supported. Results show that there are many solo librarians supporting single sites as well as multiple sites, in some cases a single librarian is supporting 10 or more sites (see Figure 3). This data reflects the results of the solo census study by McLaughlin et al [23]. The MLA Hospital Libraries Section Standards Committee published standards for hospital libraries in 2008 which included staffing [24]. In 2009, Van Moorsel studied a sample of hospitals and found that the majority did not comply with recommended staffing levels in their libraries [20]. Those standards have not been updated in over a decade and there are no current recommendations to provide guidance on the ratio of number of librarians to staff or hospitals supported.

It is of interest that very few libraries had a strategic plan (39.3\%) and even fewer had a communications or marketing plan (21.2\%). A surprisingly low percentage of libraries (59.4\%) had a website and, of those who do, just $50.0 \%$ of library can manage it themselves. Most (91.7\%) respondents had an internal library website or intranet presence but just two-thirds (66.2\%) of the staff could manage it themselves. The data on marketing plans and web presence speaks to the barriers that hospital libraries face in promoting their services or interacting with populations served. Although it may be difficult to persuade hospital information services of the need for a web presence, the need to create strategic communications and marketing plans presents an opportunity 
for educational resources and courses to be created to assist hospital librarians in understanding the benefit of and creating these plans.

It was surprising to discover that $35.6 \%$ of hospital librarians do not have or do not pay for a point of care tool, such as UpToDate or DynamedPlus. It may be that some librarians successfully eliminated costly point of care tools from their budgets or that another department pays for access to the tool. The authors speculate whether the respondents who pay for a point of care tool also pay for the majority of knowledgebased resources at their organization, even resources unique to one department or those that may not be typically thought of as library resources.

\section{Limitations}

We identified limitations that resulted from the design of the questions.

"Document delivery" and "interlibrary loan" were used to distinguish between articles supplied to users from one's collection as compared to resources requested from other libraries' collections, respectively. Respondents' comments indicated confusion over the use of these terms.

In the past, when collection formats were mostly print, there were distinct budget lines for journals and books. For the resource budget questions, it was difficult for respondents to provide accurate estimations on the total spend for resource types as some have a combination (e.g., journals, books, databases) within a single resource. Consequently, it is difficult to draw conclusions as to how much is spent on each type of resource. Related to resources, the question about point of care tools was worded so that one selection included both "does not have a point of care tool" and "does not pay for a point of care tool" whereas they should have been separate options.

Categorizing the open-ended responses for the question about library staff participation on committees was not possible as each organization has unique committee names. It was difficult to understand the scope or charge of the committees without having additional information.

\section{Future efforts}

The largest takeaway from this study is that there is a need for a concerted effort to understand baseline hospital library data in an era of increasing health care mergers and overall changes. Only once this data is collected can we begin to understand the current landscape and how to advocate for hospital libraries. Capturing data about these libraries will be challenging, as was demonstrated in this survey, and future iterations of the survey will need to address a way to collect data about health care system libraries, both those that work closely with one another and those that function independently. In order to do this, respondents may need to indicate which institutions they represent which is something not done in this survey in order to retain anonymity of respondents due to the sensitive nature of the data (especially regarding budgets). 
Current efforts at data collection include MLA's Hospital Libraries Section Census Task Force, which is charged with determining the number of hospital libraries presently in existence and the number that have closed since 2017. Once that information is collected, we suggest sending a benchmarking survey on a determined schedule (even creating a large-scale longitudinal study to set baseline data and track changes), making sure there is consistency in the questions and response choices. This will ensure we have comparable data, which should be readily available for use with administrators and for hospital library planning and advocacy.

It would be helpful to understand other changes in the hospital library profession such as staffing number changes (e.g., reduction of professional staff, mergers, retirements with or without a rehire), and changes in service responsibilities (to help determine if librarians are doing more with less). It would also be of interest to explore whether closures have impacted services in other hospital libraries or even academic libraries. With limited budgets and varying access to resources, it's possible some health systems are experiencing an environment of information inequity, or a gap in access to library resources [25]. Studies are needed that explore the short- and longterm effects of closures and mergers and their impact not only on library resources, services and budgets but also on access to information for health care providers as well as any impact on patient care outcomes. To provide the most benefit, access to future survey data for institutional comparison, such as in an online platform in which hospital library staff can input their information to see how their organization compares, would be of great benefit.

This paper presents selected results from our survey. Data associated with this article are available in the Open Science Framework at https://doi.org/10.17605/OSF.IO/5VA74. Note that identifying information, such as location within each country, has been removed.

\section{REFERENCES}

1. Kaufman Hall \& Associates LLC. 2017 in Review: the year M\&A shook the healthcare landscape. Chicago, IL; 2018.

2. Martin HJ, Delawska-Elliott B. Combining resources, combining forces: regionalizing hospital library services in a large statewide health system. J Med Libr Assoc. 2015;103(1):44-8.

3. Gibson DS, Hernandez M, Draemel A. Destination library: validating the importance of physical space. J Hosp Libr. 2015;15(3):251-61.

4. Thibodeau PL, Funk CJ. Trends in hospital librarianship and hospital library services: 1989 to 2006. J Med Libr Assoc. 2009;97(4):273-9.

5. Jones B, Honour J. Looking at MCR library closures: whats happening and why? Plains to Peaks Post: A Publication of the National Network of Libraries of Medicine, MidContinental Region. 2015;13(4):9-11.

6. Harrow A, Marks LA, Schneider D, Lyubechansky A, Aaronson E, Kysh L, et al. Hospital library closures and consolidations: a case series. J Med Libr Assoc. 2019;107(2):129-36. 
7. Giesler RH, Yast HT. A Survey of current hospital library resources. Hospitals. 1964;38:55-7. 8. Schick FL, Crawford S. Directory of health sciences libraries in the United States, 1969. Chicago: American Medical Association; 1970.

9. Crawford S, Dandurant G. Directory of Health Sciences Libraries in the United States, 1973. Chicago: American Medical Association; 1974.

10. Rees AMCS. Directory of health sciences libraries in the United States, 1979. Cleveland: Case Western Reserve University; 1980.

11. Crawford S. Health science libraries in the United States: III. Hospital health science libraries, 1969-1979. Bull Med Libr Assoc. 1983;71(1):30-6.

12. Wos M, Oddan L. Effect of institutional mergers on hospital libraries. Bull Med Libr Assoc. 1987;75(1):34-5.

13. Stevens SR. Impact of changing health care economics on Michigan hospital libraries: report of a survey. Bull Med Libr Assoc. 1990;78(2):140-5.

14. Wakeley PJ, Foster EC. A survey of health sciences libraries in hospitals: implications for the 1990s. Bull Med Libr Assoc. 1993;81(2):123-8.

15. Glitz B, Lovas I, Flack V. The changing status of hospital libraries 1984 to 1989: characteristics and services in Region 7 of the National Network of Libraries of Medicine. Bull Med Libr Assoc. 1992;80(2):179-84.

16. Dudden RF, Corcoran K, Kaplan J, Magouirk J, Rand DC, Smith BT. The Medical Library Association Benchmarking Network: development and implementation. J Med Libr Assoc. 2006;94(2):107-17.

17. Bertolucci YR, Van Houten L, Balogh L. Riding the wave from benchmarking to bucks. In: Fulda PO, Satterthwaite RK, editors. Proceedings, 103rd Annual Meeting Medical Library Association, Inc; May 4, 2003; San Diego, CA: J Med Libr Assoc; 2003. p. 117-54.

18. Fama J. "But we made the 'easy' cuts last year!" staffing the library. In: Fulda PO, Satterthwaite RK, editors. Proceedings, 104th Annual Meeting Medical Library Association, Inc; May 25, 2004; Washington, DC: J Med Libr Assoc; 2005. p. 143-88.

19. Gluck JC, Hassig RA. Raising the bar: the importance of hospital library standards in the continuing medical education accreditation process. Bull Med Libr Assoc. 2001;89(3):272-6. 20. Van Moorsel G. Analysis of compliance of hospital libraries with the Medical Library Association staffing standard: examination of the current state of the industry and reconsideration of the standard. J Hosp Libr. 2009;9(3):273-85.

21. Ducas A, Demczuk L, Macdonald K. Results of a survey to benchmark Canadian health facility libraries. J Can Health Libr Assoc. 2015;36(1):3-10.

22. Glaser BG, Strauss AL, Strutzel E. The Discovery of grounded theory: strategies for qualitative research. New York: Aldine De Gruyter; 1967.

23. McLaughlin L, Spencer A, Zeblisky K, Liszczynskyj H, Laera E. Solo census: demographics, duties, needs and challenges. J Hosp Libr. 2018;18(2):127-35.

24. Hospital Libraries Section Standards Committee, Bandy M, Doyle JD, Fladger A, Frumento KS, Girouard L, et al. Standards for hospital libraries 2007: Hospital Libraries Section Standards Committee. J Med Libr Assoc. 2008;96(2):162-9.

25. Kraft M. The Donut hole of library access. 2018 Jun 18. In: Krafty Librarian [Internet]: Michelle Kraft. [cited 2019 Jun 20]. Available from: http://www.kraftylibrarian.com/the-donuthole-of-library-access/ 